\title{
Atherogenic Index of Plasma in Postmenopausal Women
}

\author{
Gita Khakurel, ${ }^{1}$ Rajat Kayastha, ${ }^{2}$ Sanat Chalise, ${ }^{3}$ Prabin K Karki ${ }^{1}$ \\ 'Department of Physiology, Kathmandu Medical College, Duwakot, Bhaktapur, ${ }^{2}$ Department of Medicine, \\ ${ }^{3}$ Department of Pathology, Kathmandu Medical College, Sinamangal, Kathmandu, Nepal.
}

\begin{abstract}
Background: Hyperlipidemia is one of the important risk factor for development of cardiovascular disease in post menopausal women. Our study compared the serum lipid profile and atherogenic index of plasma between premenopausal and post menopausal women.

Methods: This was a cross sectional study conducted in Kathmandu Medical College. A total number of 194 women in the age group 30 to 60 years were studied. They include 108 postmenopausal women and 86 premenopausal controls. Total cholesterol, low density lipoprotein cholesterol, high density lipoprotein cholesterol and triglycerides were determined.

Results: The mean value of total cholesterol, low-density lipoprotein cholesterol and triglyceride were significantly increased in postmenopausal women when compared to premenopausal women. There was increase in high-density lipoprotein cholesterol in postmenopausal women but the difference was not significant. The atherogenic index of plasma was increased in postmenopausal women $(0.22 \pm 0.25 \mathrm{mmol} / \mathrm{l})$. This shows that postmenopausal women in our setting are at medium risk of developing cardiovascular disease. Atherogenic index of plasma was positively and significantly correlated with age $(r=0.29, \mathrm{p}<0.05)$, body mass index $(r=0.24, \mathrm{p}<0.05)$, systolic blood pressure $(\mathrm{r}=0.20, \mathrm{p}<0.05)$ and diastolic blood pressure $(\mathrm{r}=0.45, \mathrm{p}<0.05)$.

Conclusions: Postmenopausal women were at greater risk for developing cardiovascular disease when compared to premenopausal women due to increase in atherogenic lipid profile. There was a significant correlation of atherogenic index of plasma with age, body mass index, systolic blood pressure and diastolic blood pressure.

Keywords: Keywords: Atherogenic index of plasma; lipid profile; menopause.
\end{abstract}

\section{INTRODUCTION}

Menopause is "the permanent cessation of menstruation for more than one year, as a consequence of the loss of ovarian follicular activity". ${ }^{1}$ Atherogenic index of plasma (AIP) defined as log (Triglyceride/ High density lipoprotein cholesterol ( TG /HDL-C in mmol/l ) has been proposed as a marker of atherogenecity. This deranged ratio of TG to HDL-C indicates an atherogenic lipid profile and a risk for the development of myocardial infarction. ${ }^{2}$ It has been proposed that AIP values of -0.3 to 0.1 are linked with low risk, 0.1 to 0.24 with medium risk and above 0.24 with high cardiovascular risk. ${ }^{3}$ AIP is considered to be diagnostic alternative when other atherogenic risk parameters appear normal. ${ }^{4}$

Few reports of Nepalese post menopausal women are available on traditional lipid profile. ${ }^{5,6}$ But there is lack of data with respect to calculation of AIP. Hence, the aim of the present study is to assess the lipidemic status of post menopausal women by calculating the atherogenic index of plasma.

\section{METHODS}

This was a cross sectional study involving 194 women visiting the medicine out patient department (OPD) of Kathmandu Medical College during the month of MayJuly 2017. Women in the age group of 30 to 60 years were included. Ethical approval for the study was taken from the institutional review board of Kathmandu Medical College. Informed consent of the subject was taken. A detailed history was taken. Pregnant women, women with history of irregular menses, cardiovascular disease, diabetes mellitus and hypertension were excluded from the study.

The participants were classified into two groups
DOI: http://dx.doi.org/10.3126/

jnhrc.v16i2.20306 
as premenopausal and postmenopausal women. Premenopause was defined as the presence of menstruation within the past 3 months. Postmenopause was defined as the cessation of menstruation for 12 consecutive months with no other cause. ${ }^{7}$

Fasting blood samples were collected by venopuncture from the antecubital vein and was collected in the sterile tubes. The blood samples were allowed to clot and centrifuged at $3000 \mathrm{rpm}$ for 5 minutes. The serum was used for the analysis of TC, LDL-C, HDL-C and TG by automatic biochemistry analyser (Selectra). The atherogenic index of plasma (AIP) was calculated using the equation: $\log$ (TG/ HDL-C). SPSS statistical software (version 17. 0) was used to enter data in the computer and analyze it. Results were presented as mean \pm standard deviation. Independent sample t-test was used to compare the means of serum lipid profile and AIP between the premenopausal and postmenopausal groups. The Pearson correlation test was used to see the association of AIP with other variables. $p$ value $<0.05$ was considered statistically significant.

The blood pressure was measured by using the same aneroid sphygmomanometer after the participant had rested for 5 minutes. Anthropometry was conducted using standard protocol. Standing height was recorded without shoes by the measuring tape which was mounted on the wall. Weight was taken on a Krups weighing machine with light clothes and without shoes. Body mass index (BMI) in $\mathrm{kg} / \mathrm{m}^{2}$ was derived by using Quelet formula.

\section{RESULTS}

The premenopausal women were in the age group 30 to 45 years with mean age of $37.2 \pm 4.8$ years. The postmenopausal women were in the age group 48-60 years with mean age of $54.9 \pm 3.6$ years. The range of age at menopause in this study was found $44-55$ years with mean age of menopause $49.11 \pm 2.60$ years.

Table 1. Comparision of TC, LDL-C, HDL-C and TG in premenopausal and postmenopausal women $(n=194)$.

\begin{tabular}{lrrr}
$\begin{array}{l}\text { Lipid } \\
\text { profile } \\
\text { parameters }\end{array}$ & $\begin{array}{r}\text { Premenopausal } \\
\text { women }(\mathrm{n}=86) \\
\text { Mean } \pm \text { SD }\end{array}$ & $\begin{array}{r}\text { Postmenopausal } \\
\text { women }(\mathrm{n}=108) \\
\text { Mean } \pm \text { SD }\end{array}$ & $\begin{array}{r}\mathrm{p} \\
\text { value }\end{array}$ \\
\hline $\mathrm{TC}(\mathrm{mg} / \mathrm{dl})$ & $157.35 \pm 32.64$ & $198.57 \pm 43.51$ & 0.000 \\
$\begin{array}{l}\mathrm{LDL}-\mathrm{C}(\mathrm{mg} / \\
\mathrm{dl})\end{array}$ & $85.42 \pm 24.24$ & $109.98 \pm 32.48$ & 0.000 \\
$\begin{array}{l}\mathrm{HDL}-\mathrm{C} \\
(\mathrm{mg} / \mathrm{dl})\end{array}$ & $43.74 \pm 10.42$ & $44.74 \pm 9.72$ & 0.481 \\
$\mathrm{TG}(\mathrm{mg} / \mathrm{dl})$ & $127.36 \pm 76.67$ & $185.11 \pm 90.39$ & 0.000 \\
\hline
\end{tabular}

The mean HDL-C level was increased in postmenopausal women but there was no significant difference between them ( $p>0.05)$ (Table 1).

\begin{tabular}{|c|c|c|c|}
\hline Parameter & $\begin{array}{r}\text { Premenopausal } \\
\text { women }(n=86) \\
\text { Mean } \pm \text { SD }\end{array}$ & $\begin{array}{r}\text { Postmenopausal } \\
\text { women }(n=108) \\
\text { Mean } \pm \text { SD }\end{array}$ & $\begin{array}{r}p \\
\text { value }\end{array}$ \\
\hline $\begin{array}{l}\text { AIP }=\log (T G / \\
\text { HDL-C) } \\
(\mathrm{mmol} / \mathrm{l})\end{array}$ & $0.05 \pm 0.27$ & $0.22 \pm 0.25$ & 0.000 \\
\hline
\end{tabular}

Table 2 shows that the AIP value in postmenopausal women is significantly higher than the premenopausal women $(p<0.05)$.

\section{Table 3. Correlation between the atherogenic index} of plasma (AIP) and other variables.

\begin{tabular}{lrr} 
Variable & Coefficient $(r)$ & $P$ value \\
\hline Age & 0.29 & $<0.05$ \\
BMI $\left(\mathrm{kg} / \mathrm{m}^{2}\right)$ & 0.24 & $<0.05$ \\
Systolic BP $(\mathrm{mmHg})$ & 0.20 & $<0.05$ \\
Diastolic BP $(\mathrm{mmHg})$ & 0.45 & $<0.05$ \\
\hline
\end{tabular}

Table 3 shows that AIP was positively and significantly correlated with age $(r=0.29, p<0.05), B M I \quad(r=0.24$, $p<0.05)$, systolic BP $(r=0.20, p<0.05)$ and diastolic BP $(r=0.45, p<0.05)$.

\section{DISCUSSION}

The most common cause of death in postmenopausal women is coronary artery disease (CAD). Postmenopausal women are four to eight times more likely to die of CAD than of any other disease. There is 3 fold increase in CAD risk following natural menopause. ${ }^{8}$

In the present study, there were statistically significant increases in TC, LDL-C and TG in postmenopausal women than compared to premenopausal controls. These findings are in accordance with these studies 5,9,10 The transitions from premenopause to postmenopause was associated with increase in HDL-C level but the difference was not significant. It suggests that the change in HDL-C level might not be because of the loss of sex hormones. ${ }^{11}$ Similar results were observed. ${ }^{10}$ Whereas in other studies, HDL-C levels decreased significantly as a consequence of menopause. ${ }^{4,9}$ There is association of HDL-C levels with age. The level of $\mathrm{HDL}-\mathrm{C}$ increase progressively up to the $6^{\text {th }}$ decade and then decrease in females. Therefore, age may influence HDL-C levels, leading to discrepancies among studies. ${ }^{12}$ 
The mean value of AIP in premenopausal women is $0.05 \pm 0.27 \mathrm{mmol} / \mathrm{l}$ and in the postmenopausal women is $0.22 \pm 0.25 \mathrm{mmol} / \mathrm{l}$ (Table 2). The AIP is significantly increased in postmenopausal women when compared to premenopausal women $(p<0.05)$. This result is in agreement with other studies. ${ }^{2,4}$ The AIP has been used successfully as an added index for evaluating the cardiovascular risk factors. ${ }^{4}$ It has been proposed that AIP values of -0.3 to 0.1 are associated with low, 0.1 to 0.24 with medium and above 0.24 with high cardiovascular risk. ${ }^{3}$ Based on this, postmenopausal women in our setting are at a medium risk for developing CAD.

In the present study, AIP was positively and significantly correlated with age, BMI, systolic blood pressure, diastolic blood pressure which are the associated risk factors for cardiovascular disease (Table 3). Similar findings were observed in the study done in Iran. ${ }^{13}$ But another study concluded that AIP was not associated with age. ${ }^{14}$ The findings from our study was unable to explain AIP as the independent risk factor for cardiovascular disease as AIP was positively correlated with age of the women. This could be because of the limited sample size with the study being a cross sectional one. We could not assess the hormonal status of postmenopausal women. More studies are required to explain the association of AIP with other cardiovascular risk factors.

\section{CONCLUSIONS}

Postmenopausal women were at medium risk for developing cardiovascular disease. There was a significant correlation of AIP with age, BMI, systolic BP and diastolic BP. Further studies are required to explain the association between AIP and other cardiovascular risks.

\section{ACKNOWLEDGEMENTS}

We like to thank the participants, management, and laboratory staff of Kathmandu Medical College and Teaching Hospital for making this study possible.

\section{REFERENCES}

1. Research on the menopause in the 1990s. Report of a WHO Scientific Group. World Health Organisation Technical Report Series. 1996; 866: 1-107. [Full Text]

2. Umeshchandra S, Umeshchandra DG, Awanti SM. Atherogenic Index of Plasma (AIP) in postmenopausal women. Res J Pharm Biol Chem Sci.2012 ; 3(1): 519-523. [Full text]
3. Dobiasova M. AIP--atherogenic index of plasma as a significant predictor of cardiovascular risk : from research to practice.Vnitr Lek. 2006 ; 52(1): 64-71. [ [Pub Med]

4. Nwagha UI, Ikekpeazu, Ejezie FE, Neboh EE, Maduka IC. Atherogenic index of plasma as useful predictor of cardiovascular risk among postmenopausal women in Enugu, Nigeria. Afr Health Sci. 2010 ; 10(3): 248-252. [Pub Med]

5. Sapkota AS, Sapkota A, Acharya K, Raut M, Jha B. Study of metabolic syndrome in postmenopausal w o m e n . ACCLM.2015:1(1):6-11. [Full Text][DOI]

6. Pardhe BD, Ghimire S, Shakya J, Pathak S, Shakya S, Bhetwal A, et al. Biochem Res Int.2017. [Pub Med]

7. Derby CA, Crawford SL, pasternak RC, Sowers M, Sterndeld B, Matthews KA. Lipid changes during the menopause transition in relation to age and weight: The Study of Women's Health Across the Nation.Am J Epidemiol. 2009 ; 169(11): 1352-1361. [Pub Med].

8. Welty FK. Cardiovascular disease and dyslipidemia in women. Arch Intern Med. 2001; 161(4): 514-522. [Pub Med]

9. Jensen J, Nilas L, and Christiansen C. Influence of menopause on serum lipids and lipoproteins. Maturitas1990 ; 12(4): 321-331. [Pub Med]

10. Berg G, Mesch V, Boero L, Sayegh F, Prada M, Royer M, Muzzio ML, Schreier L, Siseles N, Benencia H. Lipid and lipoprotein profile in menopausal transition. Effects of hormones, age and fat distribution. Horm Metab Res. 2004 Apr;36(04):215-20.[Pub Med]

11. Cho EJ, Min YJ, Oh MS, Kwon JE, Kim JE, Lee WS, Lee KJ, Kim SW, Kim TH, Kim MA, Kim CJ. Effects of the transition from premenopause to postmenopause on lipids and lipoproteins: quantification and related parameters. Korean J Int Med. 2011 Mar;26(1):47.[Pub Med]

12. Bade G, Shah S, Nahar P, Vaidya S. Effect of menopause on lipid profile in relation to body mass index. Chronicles of Young Scientists. 2014 Jan 1;5(1):20-.[Full Text]

13. Niroumand $S$, Khajedaluee $M$, Khadem-Rezaiyan $M$, Abrishami M, Juya M, Khodaee G, Dadgarmoghaddam M. Atherogenic Index of Plasma (AIP): a marker of cardiovascular disease. Med J Islam Repub Iran. 2015;29:240.[Pub Med]

14. Nansseu JR, Moor VJ, Nouaga ME, Zing-Awona B, Tchanana G, Ketcha A. Atherogenic index of plasma and risk of cardiovascular disease among Cameroonian postmenopausal women. Lipids Health Dis. 2016 Dec;15(1):49.[Pub Med] 